\title{
Atividade hepatoprotetora do extrato alcoólico da Camellia sinensis (L.) Kuntze (chá-verde) em ratos Wistar tratados com dietilnitrosamina
}

\author{
Wanderlei Onofre Schmitz, ,'1 Rubens Cecchini, ${ }^{2}$ Dirceu Estevão, ${ }^{2}$ \\ Halha Ostrensky Saridakis ${ }^{3}$ \\ ${ }^{1}$ Centro Universitário da Grande Dourados, Unigran, Rua Balbina de Matos, 2121, \\ Jardim Universitário, 79824-900 Dourados-MS, Brasil \\ ${ }^{2}$ Departamento de Ciências Patológicas, Universidade Estadual de Londrina, Rodovia Celso Garcia Cid, \\ PR 445 km 380, Campus Universitário, 86055-900 Londrina-PR, Brasil \\ ${ }^{3}$ Departamento de Microbiologia, Universidade Estadual de Londrina, Rodovia Celso Garcia Cid, \\ PR 445 km 380, Campus Universitário, 86055-900 Londrina-PR, Brasil
}

\begin{abstract}
RESUMO: O chá-verde (Camellia sinensis (L.) Kuntze) é utilizado por suas propriedades: antioxidante, quimioprotetora e antiinflamatória em varias situações patológicas, principalmente frente a compostos químicos cancerígenos. Para tanto se avaliou o efeito hepatoprotetor do extrato de chá verde (ECV) sobre a lipoperoxidação e necrose provocada pelo agente cancerígeno Dietilnitrosamina (DEN) no fígado de ratos machos Wistar. Os ratos foram expostos a dose única de $200 \mathrm{mg} / \mathrm{kg}$ de DEN via intra peritoneal e tratados por via oral de $120 \mathrm{mg} / \mathrm{kg}$ de ECV em diferentes momentos experimentais. Após $24 \mathrm{~h}$ em relação a exposição ao DEN, os animais foram sacrificados sendo avaliado: os níveis de AST/ALT no plasma, a lipoperoxidação por quantificação de TBARS e FOX no fígado e a ocorrência de necrose e hemorragia hepática através do estudo histopatológico. A ação quimioprotetora e a diminuição da lipoperoxidação foram verificadas pela diminuição das transaminases, TBARS, FOX e redução da necrose hepática. A avaliação confirmou a importância de se utiliza o chá verde como agente quimioprotetor, principalmente na forma preventiva.
\end{abstract}

Unitermos: Camellia sinensis, Theaceae, hepatoprotetor, dietilnitrosamina, catequinas.

\begin{abstract}
Hepatic protection effect of the alcoholic extract from Camellia sinensis (L.) Kuntze (green tea) in Wistar rats treated with diethylnitrosamine". Green tea (Camellia sinensis (L.) Kuntze) is used for its properties: antioxidant, chemoprotector and anti-inflammatory in several pathological situations, mainly those facing carcinogen chemical substances. This work has evaluated the hepatic protection effect of the green tea extract (GTE) on lipoperoxidation and necrosis, induced by the carcinogenic DEN in rats' liver. Adult male Wistar rats were used and exposed to one only intra peritoneal dose of $200 \mathrm{mg} / \mathrm{kg}$ of DEN, and orally $120 \mathrm{mg} / \mathrm{kg}$ of ECV in different experimental moments. After $24 \mathrm{~h}$ of a DEN treatment, the animals were sacrificed and the following aspects were evaluated: the AST/ALT levels in plasma, lipoperoxidation of TBARS and FOX in the liver. Necrosis and Hepatic hemorrhage were observed through a histological examination. The chemoprotector action and the decrease in lipoperoxidation were detected after a decrease of AST/ALT, TBARS, FOX and hepatic necrosis. The evaluation of these results confirmed the importance of the use of the green tea as a chemoprotector agent, particularly as a preventive method.
\end{abstract}

Keywords: Camellia sinensis, Theaceae, hepatic protection, diethylnitrosamine, catechins.

\section{INTRODUÇÃO}

O chá-verde (Camellia sinensis (L.) Kuntze) é um composto rico em polifenóis, flavonóides e catequinas, que são os seus principais componentes terapêuticos. Dentre suas atividades biológicas temos: a antioxidante, quimioprotetora, anticarcinogênico e antiinflamatória. Destacando sua ação antioxidante contra os radicais livres que têm importante papel em processos patológicos como: na lesão tecidual, lesões de isquemia e reperfusão, aterosclerose, envelhecimento celular e carcinogênese (Halliwell \& Gutteridge, 1999; Morais et al., 2009).

Estas propriedades estão diretamente relacionadas coma estruturaquímica de seusflavonóides eprincipalmente com a presença de radicais hidroxil ligados aos seus anéis aromáticos (Cook \& Samman, 1996; Anghileri \& 
Thouvenot, 2000). As folhas do chá verde são ricas em catequinas cerca de $13,6 \mathrm{~g}$ de catequinas para cada $100 \mathrm{~g}$ de folhas de chá-verde. Dentro da classe das catequinas o chá apresenta: epicatequina (EC), epigalocatequina (EGC), galato-3-epicatequina (ECG), galato-3-epigalocatequina (EGCG). As catequinas correspondem a aproximadamente $26 \%$ dos compostos derivados das folhas secas do chá verde, dos quais 11\% são formados por EGCG, $10 \%$ de EGC, $2 \%$ de ECG, 2,5\% EC e 15\% de polifenóis não identificados. $\mathrm{O}$ potencial antioxidante das catequinas varia em ordem decrescente: $\mathrm{EGCG}=\mathrm{ECG}>\mathrm{EGC}=\mathrm{EC}$ e desempenham um importante papel na proteção não enzimática contra o estresse oxidativo. (Rice-Evans et al., 1996; Mello \& Santos, 2002; El Beshbishy, 2005).

Anderson et al. (2001) realizaram estudos in vitro com substância geradoras de radicais livres responsáveis por lesão no DNA, as quais foram inibidas pela adição das catequinas do chá verde. Esta atividade antioxidante das catequinas, se deve à sua capacidade de doar átomos de hidrogênio para os radicais livres, estabilizando-os (Arora et al., 1998). Cai et al., (2002) estudaram a atividade antioxidante do chá verde em microssomos de fígado de ratos, uma vez que os microssomos são semelhantes as membranas celulares e são sensíveis à lipoperoxidação de membranas por possuírem um ao alto grau de ácidos graxos poliinsaturados em sua constituição, a ação do chá verde como inibidor eficaz de lipoperoxidação destas membranas comprovam que o chá verde age como um ótimo antioxidante no organismo.

De acordo com Lin \& Liang (2000), a quimioproteção pode ser definida como: prevenção, inibição, ou reversão de carcinogênese por administração de um ou mais compostos químicos.

A dietilnitrosamina (DEN) $\left(\mathrm{C}_{4} \mathrm{H}_{10} \mathrm{~N}_{2} \mathrm{O}\right)$ é uma substância do grupo das nitrosaminas e em altas doses (200 mg/dL) pode induzir a carcinogêneses química, sendo considerado um carcinógeno completo por produzir a indução e a promoção tumoral em fígado de ratos. Ao ser metabolizado no fígado a DEN gera um composto intermediário reativo (radical livre), que induz ao processo de carcinogêneses, que é um processo com múltiplos estágios e que tem início com os focos de necrose no fígado destes animais, os focos dão origem a hepatócitos alterados e nódulos de hepatócitos hiperplásicos, sendo considerados lesões pré-neoplásicas (Velho et al., 2008).

Resultados experimentais mostraram que o chá verde é capaz de inibir o dano celular causado por diferentes carcinógenos, levando a diminuição da incidência de focos de necrose no fígado de ratos tratados com DEN e a um aumento da atividade das enzimas glutationa-S-transferase, causando um bloqueio da promoção tumoral (Cheng et al., 1991). Chen et al. (1987) e Qin et al. (1997) também relataram que a adição de chá verde $(5 \%)$ à dieta de ratos resultou em inibição da hepatocarcinogênese induzida pela aflatoxina B1, um iniciador e promotor completo da carcinogêneses .
Cao et al. (1996) testaram a ação do chá verde descafeinado na tumorigênese de fígado e pulmão, em camundongos tratados com DEN. Os autores observaram diminuição significativa no número de tumores pulmonares e hepáticos e mostraram uma relação dose-resposta na atividade quimioprotetora do chá. Este efeito também foi investigado em camundongos tratados com DEN e chá verde como fonte exclusiva de água, onde os animais apresentaram menor incidência de tumores no pulmão e do estômago, sugerindo ação inibitória na tumorigênese induzida por nitrosaminas (Wang et al., 1992).

Katiyar et al. (1993a,b) em experimento com camundongos alimentados com extrato aquoso de chá verde $(0.2 \%$ a $2.5 \%)$, observaram aumento da atividade da glutationa S-transferase e diminuição do número de focos pré-neoplásicos. Trabalhos realizados com uma fração isolada de polifenóis do chá, na dose de $5 \mathrm{mg}$ por via gástrica, 30 min antes da exposição a DEN, mostraram redução do número de tumores em camundongo. Os resultados sugerem que o chá verde possui efeito quimioprotetor na tumorigênese induzida pela DEN, atuando no aumento da atividade enzimática do metabolismo de detoxificação da fase II, ou seja, redução da disponibilidade do metabolismo tóxico da DEN (Katiyar, et al., 1993b).

Klaunig \& Kamendulis (1992) verificou o efeito do chá verde em cultura de hepatócitos de camundongos, submetidos a agentes geradores de radicais livres (paraquat e xantina oxidase), observando que o chá inibiu a morte celular induzida por estes agentes.

Chen et al. (2004) analisaram os efeitos protetores dos polifenóis do chá verde em camundongos tratados com tetracloreto de carbono $\left(\mathrm{CCl}_{4}\right)$, verificando que os polifenóis levaram à diminuição da citotoxicidade (dose-dependente) de todos os parâmetros bioquímicos e histopatológicos avaliados nos animais.

As pesquisas realizadas com chá verde indicam que este apresenta resultados benéficos para a saúde humana. Tanto que o Instituto Nacional do Câncer dos EUA iniciou um programa de utilização do chá verde como quimiopreventivo do câncer (Siddiqui et al., 2004).

Como o mecanismo de ação da DEN envolve a formação de radicais livres e lesão celular, este trabalho avaliou diferentes parâmetros bioquímicos e morfológicos que permitem verificar o efeito antioxidante e quimioprotetor do chá em um protocolo experimental. Para quantificar o efeito quimioprotetor do ECV foram utilizados vários parâmetros: dosagem de aspartato aminotransferase (AST), alanina aminotransferase (ALT), quantificação de TBARS e FOX, além do estudo histopatológico para verificar alterações morfológicas das células hepáticas dos ratos.

\section{MATERIAL E MÉTODOS}

\section{Preparo do extrato do chá verde}


O extrato de chá verde (ECV) foi preparado a partir de 300 g. de folhas secas de Camelia sinensis (L.) Kuntze. Após a extração com etanol absoluto, o produto foi filtrado em papel de filtro e concentrado em rota vapor a $40^{\circ} \mathrm{C}$, até evaporação completa do álcool, formando uma massa de extrato seco.

\section{Animais de experimentação}

Os ratos Wistar machos, pesando $200 \pm 50 \mathrm{~g}$, foram mantidos em gaiolas de polietileno com tampa de aço, com seis animais por gaiola. A ração granulada e água foram oferecidas ad libitum. A temperatura ambiente $\left( \pm 25^{\circ} \mathrm{C}\right)$, a umidade relativa do ar e o fotoperíodo $(12 \mathrm{~h} \mathrm{light} / 12 \mathrm{~h}$ dark) foram controlados. O experimento foi aprovado pelo comitê de Ética da Universidade Estadual de Londrina número: 16283/2004.

\section{Delineamento experimental}

Após uma semana de adaptação, os animais foram distribuídos aleatoriamente em cinco grupos até o término do experimento: grupo controle (controle); grupo inoculado com Dietilnitrosamina (DEN); grupo tratado com ECV (ECV); grupo tratado com ECV $3 \mathrm{~h}$ antes da DEN (ECV+DEN) e grupo tratado com ECV $12 \mathrm{~h}$ após da DEN (DEN+ECV). Os animais foram inoculados com dose única intra peritoneal de DEN (200 mg/kg) e/ou ECV via oral $(120 \mathrm{mg} / \mathrm{kg})$. Os animais foram sacrificados $24 \mathrm{~h}$ após inoculação da DEN, eles foram submetidos a anestesia por éter e deslocamento cervical. O sangue dos animais foi coletado por punção cardíaca para obtenção do soro e fragmentos do fígado foram retirados para análise histológica. Parte da amostras de fígado foram mantidos em freezer $\left(-80^{\circ} \mathrm{C}\right)$ para a quantificação das substâncias reativas ao ácido tiobarbitúrico (TBARS) e para o ensaio de complexo Fe(III)-xilenol laranja (FOX).

\section{Determinação da atividade da AST e ALT}

O método foi utilizado conforme (Reitman \& Frankel, 1957). O soro para quantificação dos parâmetros bioquímicos como: as enzimas AST e ALT, utilizando-se Kit laboratorial para a análise colorimétrica padronizada pela Laborlab Sistemas Diagnósticos Ltda.

\section{Quantificação de TBARS em fígado de ratos}

O teste do ácido tiobarbitúrico (TBARS), modificado por Cecchini et al. (1990), foi utilizado para quantificação delipoperóxidos. Ofígado foi homogeneizado na proporção de $100 \mathrm{mg}$ para $10 \mathrm{~mL}$ de tampão fosfato. Um $\mathrm{mL}$ do homogenato foi misturado a $0,2 \mathrm{~mL}$ de água destilada, $1 \mathrm{~mL}$ de TCA (28\%) e $1 \mathrm{~mL}$ de TBA. Para os tubos em que a reação de lipoperoxidação foi acelerada por ferro e ácido ascórbico foram adicionados $0,1 \mathrm{~mL}$ de cloreto férrico $(1 \mathrm{mM})$ e $0,1 \mathrm{~mL}$ de ácido ascórbico (1 $\mathrm{mM})$. Após os tubos foram homogeneizados em vortex, incubados a $95{ }^{\circ} \mathrm{C}$ por $15 \mathrm{~min}$, transferidos para banho de gelo por $5 \mathrm{~min}$. A extração foi realizada pela adição de $2 \mathrm{~mL}$ de butanol, agitação no vortex e centrifugação (centrífuga refrigerada) a $3000 \mathrm{rpm}$ por $20 \mathrm{~min}$. A leitura foi realizada a 535 e $572 \mathrm{~nm}$ em espectrofotômetro. O teste de lipoperoxidação avalia a formação de substâncias reativas ao ácido tiobarbitúrico (TBARS) e expressas em nmoles/g fígado.

\section{Ensaio de FOX (Complexo Fe(III)-Xilenol Laranja) modificado por Hermes-Lima et al. (1995)}

O fígado foi homogeneizado na proporção de $100 \mathrm{mg}$ para $10 \mathrm{~mL}$ de metanol (grau de pureza HPLC) e centrifugado a $2000 \mathrm{rpm}$ por $10 \mathrm{~min}$. Após, as reações foram preparadas com: $500 \mu \mathrm{L}$ de $\mathrm{FeSO}_{4}(1 \mathrm{mM}), 200 \mu \mathrm{L}$ de $\mathrm{H}_{2} \mathrm{SO}_{4}(0,25 \mathrm{M}), 200 \mu \mathrm{L}$ de xilenol $(1 \mathrm{mM}), 1000 \mu \mathrm{L}$ de água e $100 \mu \mathrm{L}$ de amostra. A reação foi incubada 24 h e quantificadas em espectrofotômetro a $560 \mathrm{~nm}$ contra água. Após leitura, foi adicionado aos tubos $5 \mu \mathrm{L}$ de hidroperóxido de cumeno (CHP) seguido de incubação por $30 \mathrm{~min}$ e nova leitura em $560 \mathrm{~nm}$. Os níveis de hidroperóxidos lipídicos foram expressos em equivalentes de hidroperóxido de cumeno em nmoles $\mathrm{CHP} / \mathrm{g}$ fígado. A quantidade de hidroperóxido é baseada nos hidroperóxidos que reagem com o íon metálico $\mathrm{Fe}(\mathrm{II})$. O hidroperóxido é reduzido e o ferro é oxidado em Fe(III) que forma um complexo com o Xilenol.

\section{Análise histológica}

Fragmentos do lóbulo hepático mediano dos grupos animais, foram fixados em formalina tamponada $(10 \%)$, processados e corados por hematoxilina e eosina (HE). As lâminas foram examinadas, às cegas, por dois observadores e a quantificação da hemorragia e/ou necrose centro-lobular foi realizada pela observação de dez campos, utilizando o seguinte critério: 0 (ausente), $1+$ (discreta), 2+ (moderada), 3+ (acentuada). (Estevão et al., 2002).

\section{Análise estatística}

Os resultados foram expressos em média \pm erro padrão da média. Para análise estatística utilizou-se a Análise de Variância (ANOVA) e para comparação entre as médias o Teste de Tukey. Foram considerados como estatisticamente significativos os valores de $\mathrm{p}<0,05$.

\section{RESULTADOS}

Os animais submetidos ao DEN apresentaram o peso do fígado $(9,4 \pm 0,7 \mathrm{~g})$ e o peso relativo do fígado $(3,9 \pm 0,5 \%)$ inferiores aos animais controle $(12,4 \pm 0,4 \mathrm{~g}$ e $5,1 \pm 0,2 \%)$. Já os animais tratados com o ECV 3 h antes do 
DEN apresentaram o peso do fígado $(8,6 \pm 0,6 \mathrm{~g})$ e o peso relativo do fígado $(3,7 \pm 0,3 \%)$ maiores que os apresentados pelos animais tratados com ECV $12 \mathrm{~h}$ depois do DEN $(8,2 \pm 0,4 \mathrm{~g}, 3,4 \pm 0,2 \%)$, sendo que quanto menor o peso e o peso relativo do fígado maior o quadro de lesão hepática, pois com a destruição das células hepáticas o órgão será mais leve. Os valores de transaminases (AST/ALT) aferidos nos animais tratados com ECV $3 \mathrm{~h}$ antes do DEN $(287,7 \pm 50,5 \mathrm{U} / \mathrm{L} / 195,1 \pm 28,5 \mathrm{U} / \mathrm{L})$ foram estatisticamente inferiores quando comparados com o grupo tratado com DEN $(348,6 \pm 35,8 \mathrm{U} / \mathrm{L} / 310,0 \pm 39,1 \mathrm{U} / \mathrm{L})$, já o grupo tratado com ECV $12 \mathrm{~h}$ após o DEN apresentou valores maiores $(478,0 \pm 15,2 \mathrm{U} / \mathrm{L} / 427,5 \pm 39,2 \mathrm{U} / \mathrm{L})$ que o grupo tratado com ECV $3 \mathrm{~h}$ antes da administração do DEN. Os ratos tratados com o ECV tiveram resultados de transaminases $(40,5 \pm 2,2 \mathrm{U} / \mathrm{L} / 24,9 \pm 2,6 \mathrm{U} / \mathrm{L})$ próximos aos valores do grupo controle sem tratamento algum $(44,4 \pm 2,1$ $\mathrm{U} / \mathrm{L} / 27,8 \pm 2,5 \mathrm{U} / \mathrm{L})$. O resultado do nível de hemorragia e de necrose respectivamente, do grupo tratado com DEN $(1,1 \pm 0,1 / 2,7 \pm 0,2)$ é significativamente maior quando comparado com o grupo tratado com ECV $3 \mathrm{~h}$ antes do $\operatorname{DEN}(0,3 \pm 0,2 / 1,6 \pm 0,1)$, já o grupo tratado com ECV $12 \mathrm{~h}$ após o DEN $(1,4 \pm 0,3 / 2,0 \pm 0,1)$, não apresentou diferença significativa quando comparado ao grupo tratado com o DEN (Tabela 1).

Tabela 1. Parâmetros nutricionais, bioquímicos e histopatológicos dos ratos tratados com DEN e/ou ECV.

\begin{tabular}{|c|c|c|c|c|c|c|}
\hline Parâmetros & $\begin{array}{c}\text { Fígado } 24 \mathrm{~h} \text { após } \\
\operatorname{DEN}(\mathrm{g})\end{array}$ & $\begin{array}{c}\text { Peso do fígado/100 } \mathrm{g} \text { de } \\
\text { animal (\%) }\end{array}$ & AST (U/L) & $\operatorname{ALT}(\mathrm{U} / \mathrm{L})$ & Hemorragia & Necrose \\
\hline Controle $^{(6)}$ & $12,4 \pm 0,4^{\mathrm{a}}$ & $5,1 \pm 0,2^{\mathrm{a}}$ & $44,36 \pm 2,08^{\mathrm{d}}$ & $27,78 \pm 2,48^{d}$ & $0^{\mathrm{d}}$ & $0^{\mathrm{d}}$ \\
\hline $\mathrm{DEN}^{(6)}$ & $9,4 \pm 0,7^{\mathrm{b}}$ & $3,9 \pm 0,5^{\mathrm{b}}$ & $348,6 \pm 35,8^{b}$ & $310,0 \pm 39,1^{\mathrm{b}}$ & $1,1 \pm 0,1^{\mathrm{b}}$ & $2,7 \pm 0,2^{\mathrm{a}}$ \\
\hline $\mathrm{ECV}^{(6)}$ & $12,3 \pm 0,8^{\mathrm{a}}$ & $4,8 \pm 0,4^{\mathrm{a}}$ & $40,5 \pm 2,2^{\mathrm{d}}$ & $24,9 \pm 2,6^{\mathrm{d}}$ & $0^{\mathrm{d}}$ & $0^{\mathrm{d}}$ \\
\hline $\mathrm{ECV} \mathrm{DEN}^{(6)}$ & $8,6 \pm 0,6^{b}$ & $3,7 \pm 0,3^{b}$ & $287,7 \pm 50,5^{\mathrm{c}}$ & $195,1 \pm 28,5^{\mathrm{c}}$ & $0,3 \pm 0,2^{\mathrm{c}}$ & $1,6 \pm 0,1^{\mathrm{c}}$ \\
\hline $\mathrm{DEN} / \mathrm{ECV}^{(6)}$ & $8,2 \pm 0,4^{b}$ & $3,4 \pm 0,2^{\mathrm{b}}$ & $478,0 \pm 15,2^{\mathrm{a}}$ & $427,5 \pm 39,2^{\mathrm{a}}$ & $1,4 \pm 0,3^{\mathrm{a}}$ & $2,0 \pm 0,1^{\mathrm{b}}$ \\
\hline
\end{tabular}

Controle - Grupo sem tratamento; DEN - grupo inoculado com dietilnitrosamina (dose única intra peritoneal de $200 \mathrm{mg} / \mathrm{kg}$ ); ECV - grupo tratado com ECV (dose única via oral de $120 \mathrm{mg} / \mathrm{kg}$ ); ECV+DEN - grupo tratado com ECV $3 \mathrm{~h}$ antes da DEN; DEN+ECV - grupo tratado com ECV 12 h após da DEN. ( ) = número de animais por grupo; AST - aspartato aminotransferase; ALT - alanina aminotransferase; intensidade de hemorragia e necrose: $0=$ ausente, $1+=$ discreta, $2+=$ moderada, $3+=$ acentuada; Médias seguidas por letras distintas diferem significativamente entre si em nível de $\mathrm{p}<0,05$.

Os níveis de lipoperoxidação dos lipídios das células hepáticas podem ser quantificados pela dosagem de ácido tiobarbitúrico (TBARS) por grama de fígado dos animais. $\mathrm{O}$ tratamento com ECV 3 h antes do DEN ou 12 $\mathrm{h}$ após o DEN $(0,824 \pm 0,027 \mathrm{nmol} / \mathrm{g}$ of liver $)$ apresentaram valores menores de TBARS $(0,878 \pm 0,0726 \mathrm{nmol} / \mathrm{g}$ of liver) que o grupo tratado com DEN $(1,354 \pm 0,125 \mathrm{nmol} / \mathrm{g}$ of liver) indicando ação quimioprotetora do chá verde. Já os valores dos grupos tratados com ECV $(0,620 \pm 0,018$ $\mathrm{nmol} / \mathrm{g}$ of liver) foram iguais aos encontrados no grupo controle $(0,736 \pm 0,032 \mathrm{nmol} / \mathrm{g}$ of liver $)$, indicando que o chá-verde por si só não gera radicais livres nem causa lesão as células hepáticas (Figura 1A). A quantificação de FOX do grupo tratado com ECV três horas antes do DEN (3180 $\pm 341 \mathrm{nmolCHP} / \mathrm{g}$ of liver), do grupo tratado $12 \mathrm{~h}$ após o DEN (2832 $\pm 142 \mathrm{nmolCHP} / \mathrm{g}$ of liver) são estatisticamente inferiores aos valores encontrados no grupo tratado com DEN $(4515 \pm 130 \quad \mathrm{nmolCHP} / \mathrm{g}$ of liver), confirmando diminuição da lipoperoxidação das membranas celulares e com minimização das lesões (Figura 1B). O grupo controle $(3056 \pm 217 \mathrm{nmolCHP} / \mathrm{g}$ of liver) apresentou valores semelhantes ao grupo tratado com ECV (2882 $\pm 270 \mathrm{nmolCHP} / \mathrm{g}$ of liver).

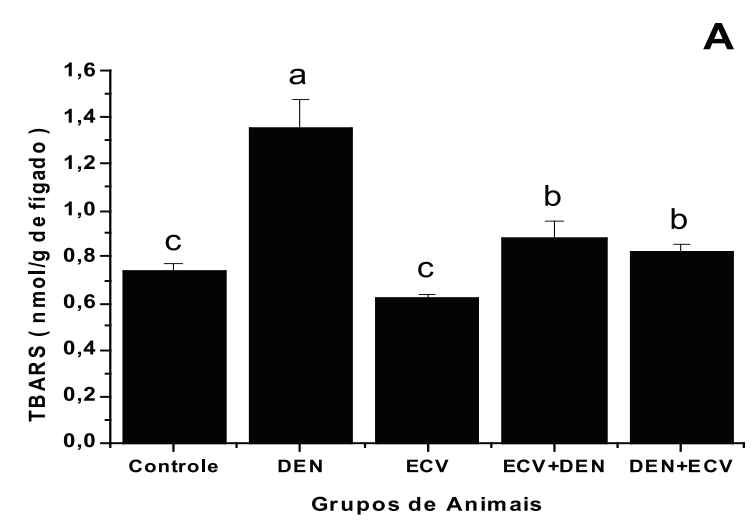

Figura 1A. Níveis de lipoperoxidação através da quantificação do ácido tiobarbitúrico (TBARS) nos ratos tratados com DEN e/ou ECV. Médias seguidas por letras distintas diferem significativamente entre si em nível de $\mathrm{p}<0,05$ (teste de Tukey). 
B (Figura 2) observam-se as imagens dos cortes histológicos:

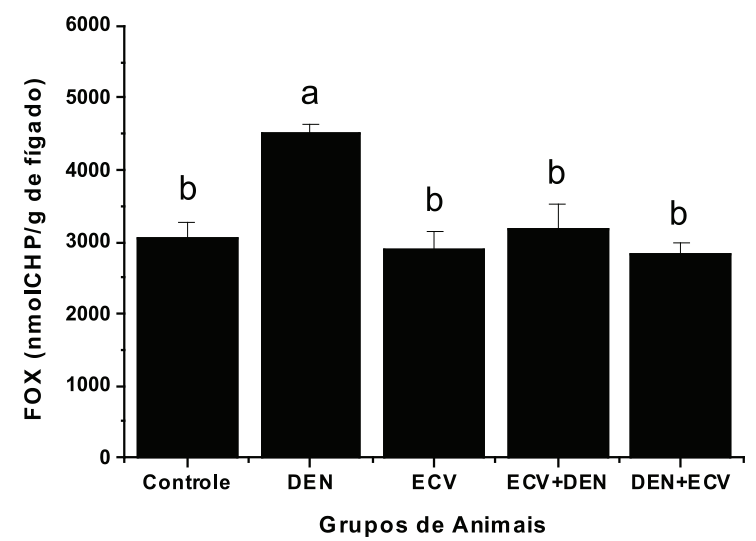

Figura 1B. Níveis de lipoperoxidação através da quantificação do Complexo Fe(III)-Xilenol Laranja (FOX) nos ratos tratados com DEN e/ou ECV. Médias seguidas por letras distintas diferem significativamente entre si em nível de $\mathrm{p}<0,05$ (teste de Tukey).

Nos resultados da avaliação histopatológica do fígado dos ratos dos diferentes grupos experimentais corte 1 , região centro-lobular do fígado controle, com células hepáticas sem lesão aparente, citoplasma bem preservado e sem alterações nucleares; corte; 2 , região de tecido hepático do grupo tratado com DEN, com focos de necrose e infiltrados celulares, sendo que na imagem menor pode-se observar a presença de hemorragia; corte 3 , região centro-lobular do fígado do grupo $\mathrm{ECV}$, onde são observadas degenerações celulares reversíveis causadas pelo acúmulo de água no interior das células, formando vacúolos citoplasmáticos perinuclear; corte 4 , região centro lobular do grupo tratado com ECV três horas antes do DEN, as lâminas apresentam focos de necrose menores que os encontrados no grupo DEN, também apresentam menor hemorragia; corte 5 , região tecidual do grupo tratado com DEN e doze horas após ECV, a imagem apresenta focos de necrose menores que do grupo DEN, porém maiores quando comparados com o grupo ECV três horas antes do DEN, confirmando uma menor quimioproteção quando o ECV é administrado após o agente lesivo, mostrando que o ECV possui ação quimioprotetora frente ao efeito citotóxico da DEN.

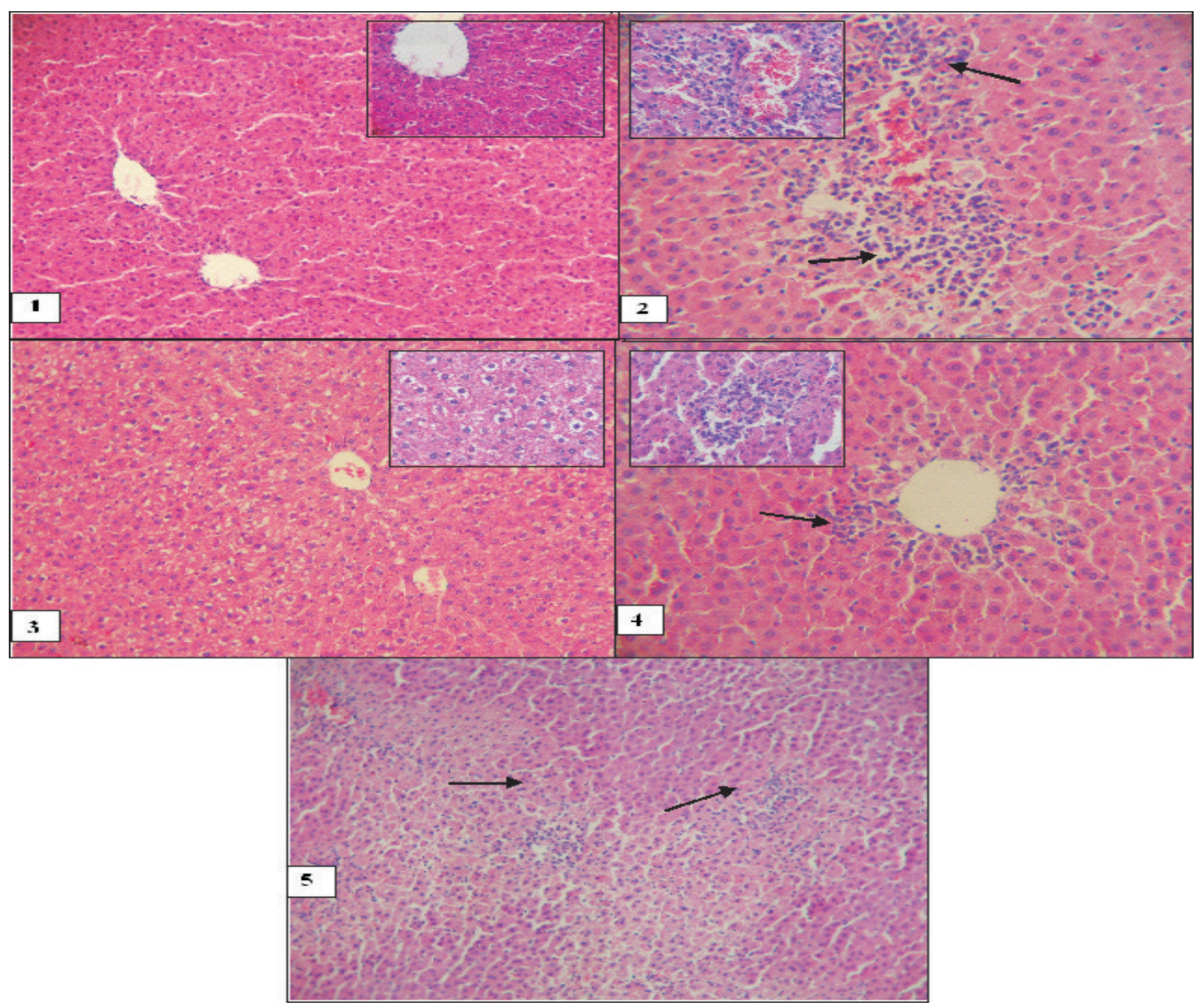

Figura 2. Estudo histopatológico do tecido hepático dos ratos. Fragmentos hepáticos do lóbulo mediano dos ratos foram processados e corados por hematoxilina e eosina (HE), aumentos 10x e 40x. ( ) indica os focos de necrose e infiltração celular nos tecidos. Imagem 1: Grupo controle, sem tratamento; Imagem 2, DEN, grupo inoculado com dietilnitrosamina (dose única intra peritoneal de $200 \mathrm{mg} / \mathrm{kg}$ ); Imagem 3, ECV, grupo tratado com ECV (dose única via oral de $120 \mathrm{mg} / \mathrm{kg}$ ); Imagem 4, ECV+DEN, grupo tratado com ECV $3 \mathrm{~h}$ antes da DEN; Imagem 5, DEN+ECV, grupo tratado com ECV 12 h após da DEN. 


\section{DISCUSSÃO}

As propriedades biológicas do chá-verde têm sido estudadas mundialmente. A avaliação de sua atividade quimioprotetora tem sido investigada em diferentes protocolos experimentais (Cheng et al., 1991; Katiyar et al., 1993a,b; Tamura et al., 1997), frente a DEN um conhecido cancerígeno que depende de ativação pelo sistema metabolizador de drogas do fígado (MFO) para exercer sua ação carcinogênica e tóxica. A participação da necrose na hepatocarcinogênese, estimulando a proliferação celular e o desenvolvimento de lesões pré-neoplásicas é necessária na etapa de iniciação da carcinogênese hepática (Haw et al., 2000, Estevão et al., 2002).

Neste estudo o grupo pré-tratado com ECV $(E C V+D E N)$ apresentou redução significativa dos valores de ALT e de AST, quando comparados com o grupo DEN, sugerindo menor lesão celular nos animais tratados com o ECV antes da DEN. No grupo pós-tratado com ECV houve aumento significativo da AST e tendência de alta da ALT, indicando aumento da lesão quando o ECV é utilizado após a intoxicação com o DEN. Este aumento pode estar relacionado com a ação dos componentes do ECV, principalmente as catequinas que possuem capacidade de se incorporar e complexar com membranas lipoprotéicas (Caturla et al., 2003). Portanto, a lesão na membrana celular causada pela DEN é aumentada pela ligação de altas concentrações de catequinas, especialmente a parte hidrofóbica mais interna desestabilizando a estrutura desta membrana (Kumazawa et al., 2004).

Tsuchiya (1999) demonstrou que as catequinas do chá-verde podem diminuir a fluidez das membranas tanto na parte hidrofílica, como hidrofóbica, sugerindo que altas doses de chá-verde podem desestabilizar a membrana e criar poros promovendo maior liberação das enzimas AST e ALT. Outro mecanismo sugere a ação pró-oxidante das catequinas em presença de metal como o cobre, provocando o aumento da permeabilidade da membrana e/ou a lateralização das proteínas da membrana gerando poros, permitindo uma maior liberação das enzimas AST/ ALT (Azam et al., 2004). O grupo tratado apenas com ECV apresentou valores de AST/ALT semelhantes ao controle, mostrando que o ECV nas concentrações utilizadas não causou injuria celular importante.

Os valores de intensidade de necrose indicam que ocorreu menor lesão nos grupos ECV+DEN e $\mathrm{DEN}+\mathrm{ECV}$ quando comparados com o grupo DEN. Os níveis do grupo ECV+DEN foram menores que do grupo DEN+ECV. Apesar de não significativo, este resultado reforça a idéia de que o ECV age melhor quando utilizado antes da intoxicação pela DEN. Os resultados encontrados neste estudo estão de acordo com os obtidos por Chen et al. (2004), que utilizando camundongos tratados com chá verde e posteriormente com tetracloreto de carbono $\left(\mathrm{CCl}_{4}\right)$ apresentaram diminuição da lesão hepática.

O comportamento do ECV difere de outros quimioprotetores clássicos com o Dietilditiocarbamato (DDTC) que atinge seu máximo de quimioproteção quatro horas após a intoxicação pela DEN, nas mesmas condições experimentais (Estevão et al., 2002). Zhu et al. (2000) demonstraram que as catequinas apresentam uma meia-vida de duas horas após o aporte oral. A meia-vida da eliminação das catequinas depois da dose oral foi de oito horas. Lee et al., 2002 também demonstraram tempos de meia-vida de três a quatro horas para EGCG e duas horas para EC/EGC. Com esta variação de tempo de meiavida dos componentes do chá, a faixa de quimioproteção é maior nos animais tratados com chá, que com outros quimiprotetores clássicos.

Destaca-se o fato na análise histopatológica do fígado dos animais tratados com ECV demonstrarem degenerações celulares reversíveis causadas pelo acúmulo de água no interior das células. Sabe-se o chá verde em altas doses pode alterar a morfologia das células hepáticas, pelo fato de suas catequinas ligarem-se a membrana plasmática desestabilizando sua estrutura, ou atuarem em nível de membrana mitocondrial levando a diminuição de produção de ATP e alterações na bomba de $\mathrm{Na} / \mathrm{K}$, estas alterações são consideradas leves e reversíveis. Schmidt et al. (2005) utilizando o chá-verde em cultural de hepatócitos de ratos observaram que altas concentrações de chá causavam citotoxicidade, confirmando em parte nossos resultados.

A lipoperoxidação das membranas celulares é acelerada pela formação de radicais livres, que clivam as duplas ligações nas estruturas dos ácidos graxos insaturados, a ação antioxidante do chá-verde é capaz de inibir a reação de lipoperoxidação. Esta capacidade foi avaliada pela dosagem das substâncias reativas ao ácido tiobarbitúrico (TBARS) e através do Complexo Fe(III)-Xilenol Laranja (FOX). Os grupos ECV+DEN e DEN+ECV apresentaram valores de TBARS e FOX significativamente inferiores aos encontrados no grupo tratado com DEN, sugerindo ação antioxidante do chá verde. Ojo et al. (2007), também observaram que o chá-verde na dose de $100 \mathrm{mg} / \mathrm{kg}$ foi capaz de diminuir a lesão hepática em ratos tratados com $10 \mathrm{mg} / \mathrm{kg}$ de oxalato de sódio que é capaz de induzir lipoperoxidação in vivo, o tratamento com chá-verde diminuiu os valores de AST/ALT e TBARS dos ratos.

Os resultados de TBARS e FOX do grupo ECV foram semelhantes aos do controle, mostrando correlação com os resultados das enzimas AST/ALT e indicando não haver lesão celular e lipoperoxidação das membranas dos animais tratados somente com ECV. Cai et al. (2002), observaram a ação antioxidante do chá em microssomas hepáticos de ratos frente ao 2,2-azobis amidinopropano dihidroclorido (AAPH). Saffari \& Sadrzadeh (2004) também verificaram que o chá verde protege a membrana de eritrócitos contra agentes lipoperoxidantes.

Além dos grupos tratados com dose única de ECV, foi realizado testes com ratos tratados com ECV 2\% via oral "ad libitum" por 35 dias. Na avaliação da ação quimioprotetora do ECV frente a DEN (200 mg/kg), os 
resultados embora não significativa, também sugeriram o efeito protetor do chá em baixas doses administrada por tempo prolongado. Os ratos tratados apenas com ECV não demonstrando efeitos tóxicos ou alterações histopatológicas após tratamento por longo período. Segundo Chen (1997) a meia vida do ECV é maior que a meia vida de suas catequinas isoladamente, fato que fortalece o uso do extrato completo como agente quimioprotetor.

O presente estudo sugere que o ECV é capaz de inibir a lipoperoxidação da célula hepática e a citotoxicidade da DEN. Diferentes autores têm demonstrado que a redução por quimioprotetores da citotoxicidade provocada pela DEN, reduz significativamente o número de focos pré-neoplásicos (Klaunig \& Kamendulis, 1999; Estevão et al., 2002). Nossos resultados sugerem que o ECV pode agir como antioxidante e quimioprotetor nas condições testadas. Tendo em vista os resultados e o possível uso do chá na medicina, outros estudos são necessários para melhor esclarecer as propriedades químicas e os mecanismos pelos quais o chá-verde pode agir como antioxidante e quimioprotetor em nosso organismo.

\section{REFERÊNCIAS}

Anderson RF, Fisher LJ, Hara Y, Harris T, Mak WB, Melton LD, Packer JE 2001. Green tea catechins partially protect DNA from $\bullet \mathrm{OH}$ radical-induced strand breaks and base damage through fast chemical repair of DNA radicals. Carcinogenesis 22: 1189-1193.

Anghileri LJ, Thouvenot P 2000. Natural polyphenols-iron interaction: its biological importance. Biol Trace Elem Res 73: 251-258.

Arora A, Muraleedharan GN, Strasburg GM 1998. Structuractivity relactionships for antioxidant activities of a series of flavonoids in a liposomal system. Free Radic Biol Med 24: 1355-1363.

Azam S, Hadi N, Khan NU, Hadi SM 2004. Prooxidant property of green tea polyphenols epicatechin and epigallocatechin3-gallate: implications for anticancer properties. Toxicol in Vitro 18: 555-561.

Cai YJ, Lan PM, Li FH, Zhou B, Yang L, Zhong LL 2002. Antioxidant effects of green tea polyphenols on free radical initiated peroxidation of rat liver microsomes. Chem Physics Lipids 120: 109-117.

Cao J, Xu Y, Chen J, Klaunig JE 1996. Chemopreventive Effects of green and black tea on pulmonary and hepatic carcinogenesis. Fundam Appl Toxicol 29: 244-250.

Caturla N, Samper EV, Villalaín J, Mateo R, Micol V 2003. The relationship between the antioxidant and the Antibacterial properties of galloylated catechins and the Structure of phospholipid model membranes. Free Radic Biol Med 34: 648-662.

Cecchini R, Aruoma OI, Halliwell B 1990. The action of hydrogen peroxide on the formation of thiobarbituric acid-reative material from microssomes or from DNA damage bybleomycin or phenamthroline. Artefactis in the thiobarbituric acid test. Free Radic Res Commun 10: 245-258.

Chen JH, Tipoe GL, Liong EC, So HSH, Leung KM, Tom WM, Fung PCW, Nanji AA 2004. Green tea polyphenols prevent toxin-induced hepatotoxicity in mice by downregulating inducible nitric oxide-derived prooxidants. Am J Clin Nutr 80: 742-751.

Chen L, Lee MJ, Li H, Yang CS 1997. Absorption, distribution, and elimination of tea polyphenols in rats. Drug Metab Dispos 25: 1045-1050.

Chen ZY, Yan RQ, Qin GZ, Qin LL 1987. Effect of six edible plants on the development of aflatoxin B1-induced y-glutamyltranspeptidase positive hepatocytefoci in rats. Chin J Oncol 9: 109-111.

Cheng S, Ding L, Zhen Y, Lin P, Zhu Y, Chen Y, Hu X 1991. Progress in studies on the antimutagenicity and anticarcinogenicity of green tea epicatechins. Chin Med Sci 6: 233-238.

Cook NC, Samman S 1996. Flavonoids-chemistry, metabolism, cardioprotective effects, and dietary sources. Nutr Biochem 7: 66-76.

El-Beshbishy HA 2005. Hepatoprotective Effect of green tea (Camellia sinensis) extract against tamoxifen-induced liver injury in rats $J$ Biochem Mol Biol 38: 563-570.

Estevão D, Saito AY, Gualtieri KA 2002. Proctetive effect by diethyldithilcarbamate on hepatocytic and preneoplastic foci induced by diethylnitrosamine. Biosaude 4: 37-50.

Halliwell B, Gutteridge JMC 1999. Free radicals in biology and medicine. 3 ed., Oxford: University Press, Cap. 1-3, 1-245.

Hwa KL, Hack SK, Hong SC, Seikwan O, Jongwon C 2000. Hepatoprotective effects of bergenin, a major constituent of Mallotus japonicus, on carbon tetrachlorideintoxicated rats. J Ethnopharmacol 72: 469-474.

Hermes-Lima M, Willmore WG, Storey KB 1995. Quantification of lipid peroxidation in tissue based on the Fe(III)Xylenol orange complex formation. Free Radic Biol Med 19: 271-280.

Katiyar SK, Agarwal R, Zaim MT, Mukhtar H 1993a. Protection against $\mathrm{N}$-nitrosodiethylamine and benzo[a]pyreneinduced forestomach and lung tumorigenesis in $\mathrm{A} / \mathrm{J}$ mice by green tea. Carcinogenesis 14: 849-855.

Katiyar SK, Agarwal R, Mukhtar H 1993b. Protective effects of green tea polyphenols administered by oral intubation against chemical carcinogen-induced forestomach and pulmonary neoplasia in A/J mice. Cancer Lett 73: 167172.

Klaunig JE, Kamendulis LM 1999. Mechanisms of cancer chemoprevention in hepatic carcinogenesis: moduletion of focal lesion grouwth in mice. Toxicol Sci 52: 101106.

Kumazawa S, Kajiya K, Naito A, Saitô H, Tuzi S, Tanio M, Suzuki M, Nanjo F, Suzuki E, Nakayama T 2004. Direct evidence of interaction of green tea polyphenols, epigallocatechin gallate, with lipid bilayers by solid-state nuclear magnetic resonance. Biosci Biotechnol Biochem 
68: 1743-1747.

Lee MJ, Maliakal P, Chen L, Meng X, Bondoc FY, Prabhu S, Lambert G, Mohr S, Yang CS 2002. Pharmacokinetics of tea catechins after ingestion of green tea and (-)-epigallocatechin-3-gallate by humans: formation of different metabolites and individual variability. Cancer Epidemiol Biomarkers Prev 11: 1025-1032.

Lin JK, Liang YC 2000. Cancer chemoprevention by tea polyphenols. Proc Natl Sci Counc 24: 1-13.

Mello JCP, Santos SC Taninos In Simões MO, Schenkel EP, Gosmann G, Mello JCP, Mentz LA, Petrovick PR 2002. Farmacognosia da Planta ao Medicamento, Santa Catarina: UFSC, Cap. 24, 527-554.

Morais SM, Cavalcanti ESB, Costa SMO, Aguiar LA 2009. Ação antioxidante de chás e condimentos de grande consumo no Brasil. Rev Bras Farmacogn 19: 315-320.

Ojo OO, Ladeji O, Nadro MS 2007. Studies of the antioxidative effects of green and black tea (Camellia sinensis) extracts in rats J Med Food 10: 345-349.

Qin G, Kriczky G, Su J, Ning Y, Lotlikar PD 1997. Inhibition of aflatoxin B1-induced initiation of hepatocarcinogenesis in the rat by green tea. Cancer Lett 112: 149-154.

Reitman S, Frankel S 1957. A colorimetric method for the determination of serum glutamic oxalacetic and glutamic pyruvic transaminases. Am J Clin Pathol 28: 56-63.

Rice-Evans CA, Miller NJ, Paganga G 1996. Structure-antioxidant activity relationships of flavonoids and phenolic acids. Free Radic Biol Med 20: 933-956.

Saffari Y, Sadrzadeh SM 2004. Green tea metabolite EGCG protects membranes against oxidative damage in vitro. Life Sci 74: 1513-1518.

Schmidt M, Schmitz HJ, Baumgart A, Guédon D, Netsch MI, Kreuter MH, Schmidlin CB, Schrenk D 2005. Toxicity of green tea extracts and their constituents in rat hepatocytes in primary culture. Food Chem Toxicol 43: 307-314.

Siddiqui IA, Afaq F, Adhami VM, Ahmad N, Mukhtar H 2004. Antioxidants of the beverage tea in promotion of human health. Antioxid Redox Signal 6: 571-582.

Tamura K, Nakae D, Horiguchi K, Akai H, Kobayashi Y, Satoh H, Tsujiuchi T, Denda A, Konishi Y 1997. Inhibition by green tea extract of diethylnitrosamine-initiated but not choline-deficient, L-amino acid-defined diet-associated development of putative preneoplastic, glutathione S-transferase placental form-positive lesions in rat liver. Jpn J Cancer Res 88: 356-362.

Tsuchiya H 1999. Effects of green tea catechins on membrane fluidity. Pharmacol 59: 34-44.

Velho AV, Hartmann AA, Kruel CDP 2008. Effect of black tea in diethylnitrosamine-induced esophageal carcinogenesis in mice. Acta Cirugica Bras 23: 329-336.

Wang ZY, Jun YH, Mou TH, Kenneth RR, Allan HC, Chung SY 1992. Inhibition of N-nitrosodiethylamine- and 4-(methylnitrosamino)-1-(3-pyridyl)-1-butanoneinduced tumorigenesis in $\mathrm{A} / \mathrm{J}$ mice by green tea and black tea. Cancer Res 52: 1943-1947.

Zhu M, Chen Y, Li RC 2000. Oral absorption and bioavailability of tea catechins. Planta Med 66: 444-47. 